This document is confidential and is proprietary to the American Chemical Society and its authors. Do not copy or disclose without written permission. If you have received this item in error, notify the sender and delete all copies.

\title{
An Unexpected Hydrated Electron Source for Preparative Visible-Light Driven Photoredox Catalysis
}

\begin{tabular}{|c|c|}
\hline Journal: & Journal of the American Chemical Society \\
\hline Manuscript ID & ja-2018-12223x.R1 \\
\hline Manuscript Type: & Article \\
\hline $\begin{array}{r}\text { Date Submitted by the } \\
\text { Author: }\end{array}$ & 20-Dec-2018 \\
\hline Complete List of Authors: & $\begin{array}{l}\text { Kerzig, Christoph; Universitat Basel Departement Chemie } \\
\text { Guo, Xingwei; Universitat Basel, Department of Chemistry } \\
\text { Wenger, Oliver; Universitat Basel, Department of Chemistry }\end{array}$ \\
\hline
\end{tabular}

\section{SCHOLARONE \\ Manuscripts}




\section{INTRODUCTION}

Many important chemical reactions require very strong reductants, but photocatalytic mechanisms driven by a single visible photon can only provide limited reducing power. For instance, the widely used $\operatorname{Ir}(\mathrm{ppy})_{3}$ complex is capable of reducing aryl iodides and bromides, ${ }^{1}$ but aryl chlorides are out of range and require multi-photon excitation processes when using visible photons. ${ }^{2}$ In 2014, the interest in two-photon approaches received a boost by the discovery of novel mechanisms ${ }^{2,3}$ with far-reaching laboratory applications for reductive transformations, in organic solvents $^{4-9}$ and water ${ }^{10-13}$. Given that intense irradiation is required for two-photon mechanisms to be efficient, the availability of cheap light sources with high photon fluxes such as high-power LEDs and cw lasers laid the grounds for the ongoing rapid development ${ }^{14-25}$ in that research field.

Concerning challenging reductions in aqueous solution, the hydrated electron $\left(\mathrm{e}_{\mathrm{aq}}{ }^{-}\right)$is the most promising initiating species, because with a standard potential as high as that of alkali metals $(-2.9 \mathrm{~V} \text { vs. } \mathrm{NHE})^{26}$ and a lifetime much longer than excited singlet or doublet states can possess (about $1 \mu$ s under conditions suitable for applications), that species provides the perfect balance between thermodynamic and kinetic reactivity. Two basic pathways for the catalytic generation of $\mathrm{e}_{\mathrm{aq}}{ }^{--}$are conceivable, which both consume two visible photons and a sacrificial donor. ${ }^{3,27}$ Following the first light absorption event by the catalyst, the excited state is either directly photoionized producing the one-electron oxidized form of the catalyst as by-product (Fig. 1b), ${ }^{27}$ or a photoinduced electron transfer converts the catalyst

into its one-electron reduced form serving as $\mathrm{e}_{\mathrm{aq}}{ }^{--}$precursor (Fig. 1a). ${ }^{3}$ Whereas the applicability of both mechanisms was demonstrated using pulsed lasers for illumination, ${ }^{10,27,28}$ so far only the latter pathway has been viable with non-pulsed light sources such as those nowadays available in most chemistry laboratories. ${ }^{11-13}$ However, these recent studies rely on the exploitation of anionic micelles ${ }^{11,12}$ or sophisticated Coulombic interactions $^{13}$ to stabilize relevant reaction intermediates, rendering these methods somewhat cumbersome.

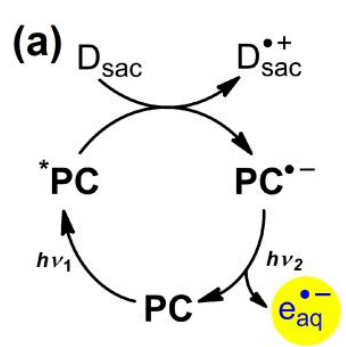

(c)

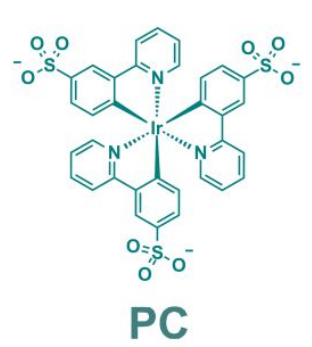

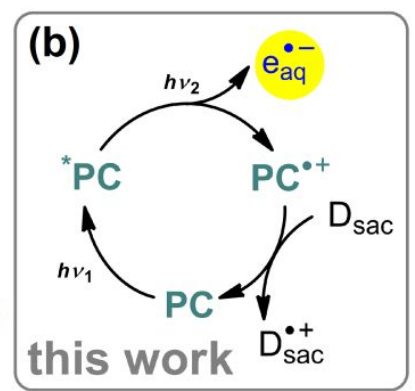

(d)

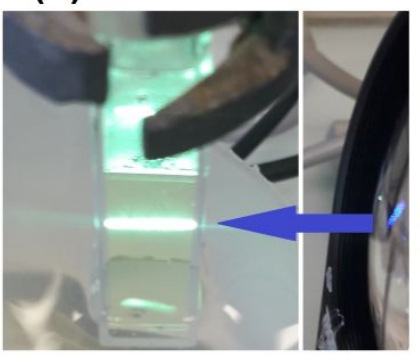

Figure 1. (a) Catalytic cycle of aqueous radical anion photoionization. ${ }^{3}$ (b) Catalytic generation of $\mathrm{e}_{\mathrm{aq}}{ }^{-}$- through the visiblelight driven ionization of the photocatalyst (PC) Irsppy (structure given in (c)) with subsequent catalyst regeneration using a sacrificial donor $\mathrm{D}_{\text {sac. }}$ (d) Photograph showing the experimental conditions required for the novel $\mathrm{e}_{\mathrm{aq}}{ }^{-{ }^{-}}$production system; the key point is the beam collimation of a blue cw laser $(447 \mathrm{~nm}, 1 \mathrm{~W})$ to a spot smaller than $1 \mathrm{~mm}^{2}$ (as visualized by the catalyst emission). For further explanations, see text and SI (Section 1.2).

During the last decade, $\mathrm{e}_{\mathrm{aq}}{ }^{-\boldsymbol{}}$ has been employed for the decomposition of persistent halogenated pollutants, ${ }^{29}$ for nitrogen $^{30}$ or carbon dioxide fixation, ${ }^{31}$ as well as for versatile chemical syntheses. ${ }^{11-13}$ However, the lack of easy-to-handle visible light-driven $\mathrm{e}_{\mathrm{aq}}{ }^{-}$sources still hampers its broad usage. 
This initiated our quest for a novel catalytic system operating in pure water without relying on supramolecular interactions. As we will show by addressing both detailed mechanistic investigations and preparative photoredox catalysis (see Supporting Information (SI) for details), a water-soluble analogue of $f a c-\operatorname{Ir}(\text { ppy })_{3}$ (Irsppy, Fig. 1c $)^{32}$ has ideal properties to act as a photocatalyst for $\mathrm{e}_{\mathrm{aq}}{ }^{\bullet-}$ production via the mechanism of Fig. 1b. In contrast to the longstanding opinion that pulsed lasers $(\sim 20000$ \$) with power densities of about $100 \mathrm{MW} \mathrm{cm}{ }^{-2}$ are required for that mechanism to work, , $^{3,6,27}$ we will demonstrate preparative-scale applications with an inexpensive ( $1000 \$)$ blue cw laser and optics for beam collimation (Fig. 1d), whose combination ensures a photon flux per area on the order of $1 \mathrm{~kW} \mathrm{~cm}^{-2}$ (SI, Section 1.2).

\section{RESULTS AND DISCUSSION}

Mechanistic investigations. Our trisulfonated Irsppy is a perfect water-soluble stand-in for its famous parent compound $\mathrm{fac}$ $\operatorname{Ir}(\text { ppy })_{3},{ }^{33}$ as the photophysical properties presented in Fig. 2a demonstrate: its ground state absorbs below $500 \mathrm{~nm}$ (cyan trace), the ${ }^{3}$ MLCT shows characteristic green luminescence (light green trace) with a very high quantum yield, and the emissive excited state decays with a lifetime of about $1.6 \mu \mathrm{s}$, which is shown in the inset of Fig. 2a by time-resolved luminescence $(510 \mathrm{~nm})$, excitedstate absorption (367 $\mathrm{nm})$ and ground-state bleaching measurements $(278 \mathrm{~nm})$. Beyond these steady-state and lifetime experiments, we carefully corrected and calibrated the excitedstate absorption spectrum of Irsppy (orange trace in Fig. 2a, see SI for details), which forms the basis for quantitative measurements.

Thermodynamic considerations (SI, Section 3) predict the photoionization (i.e., the light-driven release of $\mathrm{e}_{\mathrm{aq}}{ }^{--}$) of excited Irsppy ( ${ }^{3}$ Irsppy) to be more favourable than that of excited ruthenium(tris)bipyridine ${ }^{34}\left[\mathrm{Ru}(\mathrm{bpy})_{3}\right]^{2+}$ by about $0.6 \mathrm{eV}$. The ionization of ${ }^{3}\left[\mathrm{Ru}(\mathrm{bpy})_{3}\right]^{2+}$ requires highly energetic photons $(\lambda<$ $400 \mathrm{~nm})^{3,35,36}$ and therefore we anticipated that the absorption of a second low-energy photon by ${ }^{3}$ Irsppy might result in efficient $\mathrm{e}_{\mathrm{aq}}{ }^{\bullet-}$ formation via an "all-visible" biphotonic ionization mechanism (mechanism of Fig. 1b). To test this, we performed two-pulse laser flash photolysis ${ }^{23,28,37,38}$ using a pulse sequence as illustrated at the top of Fig. 2b. An initial $430 \mathrm{~nm}$ pulse was followed by a $532 \mathrm{~nm}$ pulse (delayed by $450 \mathrm{~ns}$ ). This allowed the generation of ${ }^{3}$ Irsppy with the first pulse, whilst the second pulse $(532 \mathrm{~nm})$ selectively excites that ${ }^{3}$ Irsppy photoproduct (vertical lines in Fig. 2a; SI, pages S12-S15). The second pulse brings about ${ }^{3}$ Irsppy bleaching on a large scale (Fig. 2b, blue trace), as is evidenced by two-pulse experiments with luminescence detection $(\lambda=510 \mathrm{~nm})$, since these measurements are able to monitor ${ }^{3}$ Irsppy (the proposed intermediate in our consecutive two-photon mechanism) without interferences from other species (see Section 6 of the SI for details). Monitoring additional transient absorptions under the same experimental conditions revealed the appearance of a new second-pulse induced species absorbing in the red and possessing a $1.4 \mu$ s lifetime. Quenching experiments of the absorptions of this species with chloroacetate $\left(\mathrm{ClAc}^{-}\right.$, Fig. 2c) yielded a rate constant $\left(1.15 \times 10^{9} \mathrm{M}^{-1} \mathrm{~s}^{-1}\right)$ practically identical with that previously observed for the reaction between $\mathrm{e}_{\mathrm{aq}}{ }^{\bullet-}$ and $\mathrm{ClAc}^{-},{ }^{26}$ which is a reliable reference reaction. ${ }^{11,28,29}$ Control experiments established that ${ }^{3}$ Irsppy itself does not react with chloroacetate (SI, last paragraph of Section 5). All these results, together with additional two-pulse experiments with spectral detection (SI, Section 6), unambiguously identify the new species as $\mathrm{e}_{\mathrm{aq}}{ }^{\bullet}$. By changing the energy of the second pulse with all other parameters unmodified, the intensity dependence of $\mathrm{e}_{\mathrm{aq}}{ }^{\bullet-}$ formation was obtained. That dependence (Fig. 2b, inset) exhibits
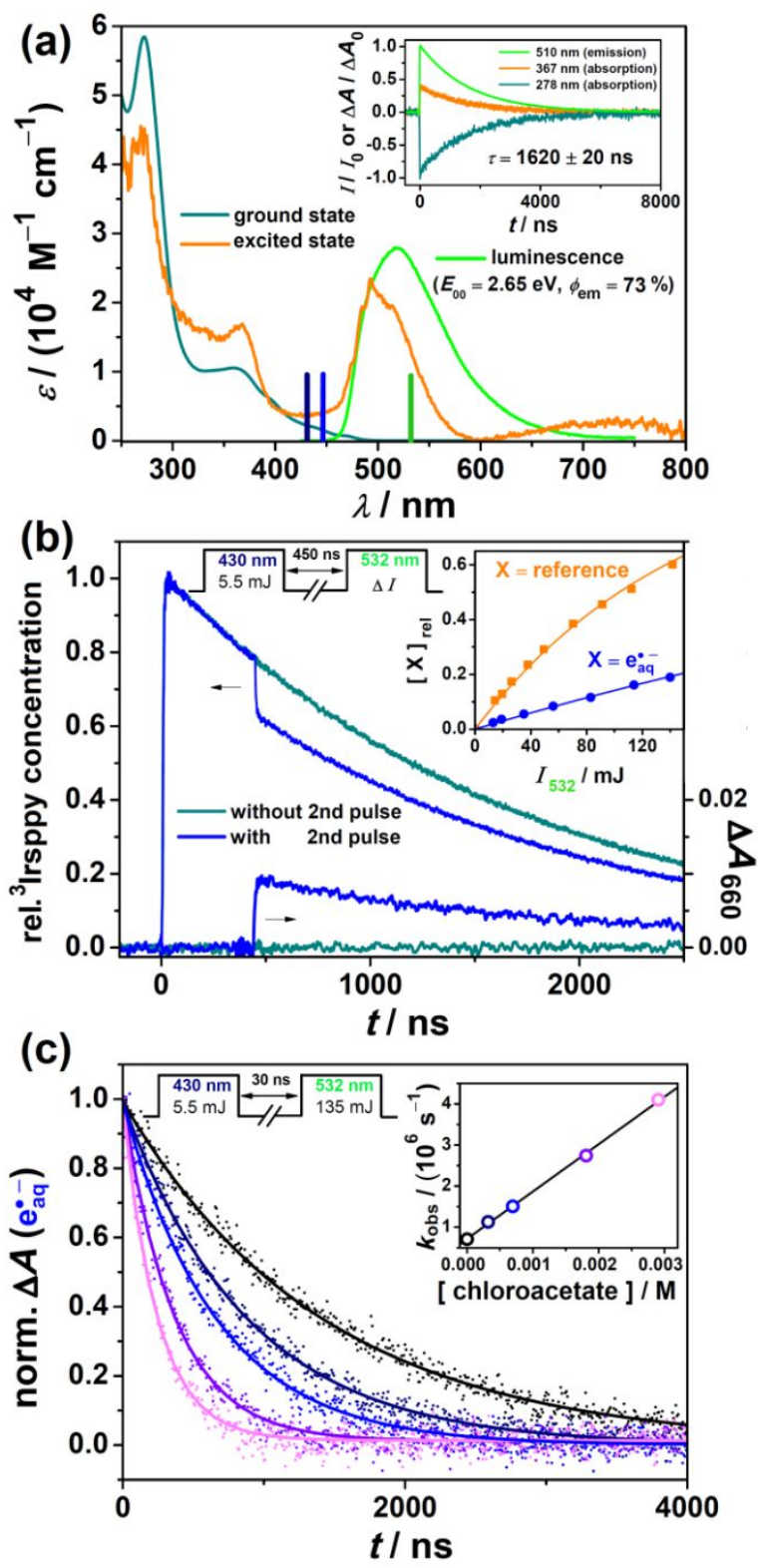

Figure 2. Photochemical properties of Irsppy in its ground and excited state (panel a); two-pulse experiments on the photoionization mechanism (Fig. 1b) of Irsppy (panel b); and unambiguous identification of $\mathrm{e}_{\mathrm{aq}}{ }^{\bullet-}$ as product by monitoring its reaction with chloroacetate $\mathrm{ClAc}^{-}$(panel c). All experiments carried out in Ar-saturated aq. solutions containing $50 \mu \mathrm{M}$ Irsppy. (a) Calibrated absorption and corrected luminescence spectra; wavelengths used for excitation (laser flash photolysis, 430 and $532 \mathrm{~nm}$; prep. photolysis, $447 \mathrm{~nm}$ ) indicated as vertical lines. Inset, kinetic traces upon excitation with $430 \mathrm{~nm}$ laser pulses $(5 \mathrm{~mJ})$. (b) Kinetic data for excited Irsppy (upper traces, left y-axis) and $\mathrm{e}_{\mathrm{aq}}{ }^{\bullet-}$ (lower traces, right y-axis) in a representative two-pulse experiment (pulse scheme above traces) with the second laser $(135 \mathrm{~mJ})$ blocked (cyan) or unblocked (blue). Inset, excited Irsppy bleaching $/ \mathrm{e}_{\mathrm{aq}}{ }^{\bullet-}$ formation (blue) at different intensities of the second laser and reference reaction (excitation of $\left[\mathrm{Ru}(\mathrm{bpy})_{3}\right]^{2+}$, orange) used for relative actinometry, both relative to the prepulse concentration of the respective signal precursor. (c) Experimental $\mathrm{e}_{\mathrm{aq}}{ }^{\bullet-}$ decay (dots) in the presence of variable amounts of $\mathrm{ClAc}^{-}$after excitation with the pulse scheme shown above the traces. Inset, corresponding Stern-Volmer plot. For further details, see text and SI. 

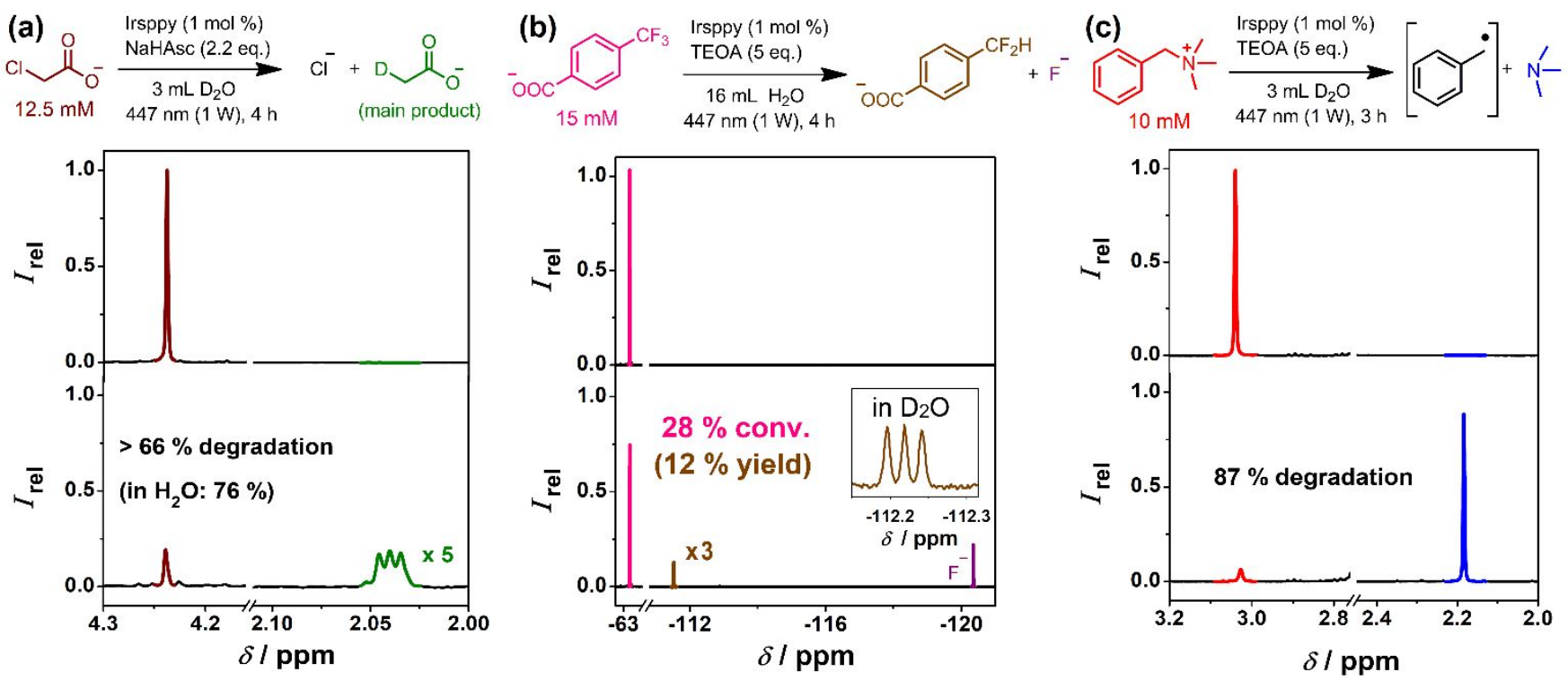

Figure 3. Lab-scale reactions carried out with the new blue-light driven $\mathrm{e}_{\mathrm{aq}}{ }^{-{ }^{-}}$source in $\mathrm{Ar}$-saturated solution with the pertinent conditions given at the respective equations. (a) Detoxification of $\mathrm{ClAc}^{-}$. (b) Monodefluorination of 4-(trifluoromethyl)benzoate. (c) Degradation of the benzyltrimethylammonium cation. Quantitative NMR measurements $\left(\mathrm{ClAc}^{-}\right.$and benzyltrimethylammonium cation, ${ }^{1} \mathrm{H}$ NMR; 4(trifluoromethyl)benzoate, ${ }^{19} \mathrm{~F}$ NMR) are displayed before (upper trace) and after (lower trace) irradiation; the same color codes as in the reaction equations have been used. For further details, see the text and SI Sections 1 and 7.

a linear low-intensity regime indicating the ${ }^{3}$ Irsppy ionization to be monophotonic. Relative actinometry with the excitation of $\left[\mathrm{Ru}(\mathrm{bpy})_{3}\right]^{2+}$ as reference ${ }^{28,35}$ (SI, Section 6) gave a quantum yield of $1.3 \%$ for the green-light ionization of ${ }^{3}$ Irsppy.

Compared to a two-photon mechanism with quasi-persistent radical anions as intermediates (Fig. 1a), the mechanism of Fig. $1 \mathrm{~b}$ with rather short-lived excited states unavoidably militates for many unproductive catalyst excitations. This prompted us to study the stability of our catalyst. In comparative stability assays using blue light (SI, Section 2) Irsppy turned out to be much more photostable than the widely-employed catalyst $\left[\mathrm{Ru}(\mathrm{bpy})_{3}\right]^{2+}$.

With the insights gained in both the ionization mechanism and the catalyst stability, the lab-scale application of our novel $\mathrm{e}_{\mathrm{aq}}{ }^{\bullet-}$ source to challenging reductions became a realistic objective. With an excited-state oxidation potential of $-1.64 \mathrm{~V} v s$. NHE, ${ }^{3}$ Irsppy is itself capable of reducing numerous compounds. In addition to imine reduction, ${ }^{32}$ we observed the direct reductive acetophenone activation with a rate constant close to the diffusion limit and the preparative dehalogenation of 4-chlorobenzoic acid (SI, page S9), i.e., two reactions that hitherto required $\mathrm{e}_{\mathrm{aq}}{ }^{\bullet-}$ to be initiated in aqueous solution. ${ }^{10,12}$ On these grounds, we carefully performed control experiments (see SI) with all substrates of Fig. 3 and confirmed that catalyst-derived species do not contribute to the observed lab-scale transformations.

Applications of the novel hydrated electron source. We first investigated the preparative dehalogenation of $\mathrm{ClAc}^{-}$using a collimated $447 \mathrm{~nm}$ diode laser (SI, Section 7), which can excite both Irsppy and ${ }^{3}$ Irsppy (blue vertical line in Fig. 2a), and employed ascorbate $\left(\mathrm{HAsc}^{-}\right)$because that sacrificial donor is known to reduce the one-electron oxidized catalyst ${ }^{32}$ thereby completing the catalytic photoionization mechanism of Fig. $1 \mathrm{~b}$.

${ }^{1} \mathrm{H}$ NMR studies revealed the successful catalytic decomposition of $66 \%$ (Fig. 3a, lower limit due to interferences with other
NMR signals) of that model compound for recalcitrant and toxic chloro-organics, ${ }^{10,27,29}$ together with the formation of acetic acid as main product (SI, Section 7.1). Since no other species in our system than $\mathrm{e}_{\mathrm{aq}}{ }^{-}$is able to reduce non-activated chloro-organics, the reaction must occur via the $\mathrm{e}_{\mathrm{aq}}{ }^{-}$- induced dissociative electron transfer. ${ }^{29}$ That reasoning is further substantiated by the electrochemical detection of chloride ions corresponding to $76 \%$ conversion. Furthermore, we carried out chloroacetate degradation experiments at different excitation power densities. The photon flux per area was either modified by changing the beam size (SI, Section 1.2) or the total output of our light source (SI, Section 7.1, Figure S11). Both sets of experiments confirmed the biphotonic character (mechanism of Fig. 1b) of the catalytic photoreaction.

We next tested triethanolamine (TEOA) as sacrificial donor, since that donor is not prone to fast oxidation in solution facilitating the experimental procedure. Under standardized conditions, we indeed observed efficient $\mathrm{ClAc}^{-}$dechlorination with a TON as high as 203 , whereas in experiments with $\left[\mathrm{Ru}(\mathrm{bpy})_{3}\right]^{2+}$ there is no $\mathrm{ClAc}^{-}$conversion at all, only rapid catalyst decomposition (SI, Section 7.1). These experiments clearly demonstrate that the combination of a highly stable photocatalyst with favorable thermodynamic properties and a collimated cw laser allows production of the superreductant $\mathrm{e}_{\mathrm{aq}}{ }^{\bullet-}$ for laboratory applications. Compared to other photoredox studies relying on two-photon excitation, our TON of 203 is encouraging. For reference, dehalogenation reactions with Rhodamine $6 \mathrm{G}^{5}$ or perylene diimide (PDI) ${ }^{2}$ seemed to require catalyst loadings of at least $5 \%$, limiting the maximum achievable TON to 20 .

Subsequently, we turned to the activation of trifluoromethylarenes, which is currently of significant interest in pharmaceutical research. ${ }^{39}$ In contrast to the only photoredox strategy available for that task, ${ }^{40}$ an $\mathrm{e}_{\mathrm{aq}}{ }^{-}$based approach for the direct reduction would likely not be limited to activated trifluoromethylarenes 
with strongly electron-withdrawing groups. Our first try with the model compound 4-(trifluoromethyl)benzoate afforded a conversion of $66 \%$, but yielded only traces of the desired monodefluorinated product. However, by simply switching off the light once the maximum concentration of 4-(difluoromethyl)benzoate is reached, quite promising results (Fig. $3 b$ ) were obtained given the well-known selectivity problems of such reactions. ${ }^{36}$ Simultaneously, we upscaled the reaction and extracted a crude product $(30 \mathrm{mg})$ containing 4-(trifluoromethyl)benzoate and 4(difluoromethyl)benzoate in a 6/1 ratio (SI, Section 7.2), showing the usefulness of our method for larger-scale applications. The reaction yield is still low, but the proof-of-concept is now made. Separation of that mixture (compare, main plot of Fig. S12) was not carried out. However, the isolation of 4-(difluoromethyl)benzoic acid might be feasible via column chromatography ${ }^{41}$ or preparative $\mathrm{HPLC}^{42}$. Given that difluoromethylarenes - if commercially available at all - are usually much more expensive than the corresponding trifluoromethyl derivatives, both the further optimization of our catalytic system and its application to other defluorination reactions seem worthy of further investigation in future studies.

Prior spectroscopic investigations using pulse radiolysis gave a rate constant for the direct reduction of trifluoromethylbenzene by $\mathrm{e}_{\mathrm{aq}}{ }^{\bullet-}$ as high as $1.8 \times 10^{9} \mathrm{M}^{-1} \mathrm{~s}^{-1} .^{43}$ Hence, the $\mathrm{e}_{\mathrm{aq}}{ }^{\bullet-}$ induced activation (with subsequent defluorination) should in principle be applicable to a very broad range of trifluoromethylarenes. Another attractive feature of our method is that deuteration ${ }^{12,44}$ of intermediate radicals is feasible when the reactions are carried out in heavy water, which is illustrated by the 1:1:1 triplets of both the $\mathrm{CH}_{2}$ NMR signal in Fig. $3 \mathrm{a}$ and the $\mathrm{CF}_{2}$ NMR signal in Fig. $3 \mathrm{~b}$ (inset of the figure).

Finally, we addressed the reduction of quaternary ammonium compounds (QACs). QACs are large-scale industrial products with many applications; however, their stability (hampering the degradation during wastewater treatment) causes accumulation of QACs in the environment. ${ }^{45}$ Although QACs have long been known to be environmentally risky, the quest for efficient QAC elimination procedures is still ongoing. Using the benzyltrimethylammonium cation, which is the basic structure of many QACs, we observed very efficient degradation with our photocatalytic system (Fig. 3c and SI). We regard our novel labscale approach relying on $\mathrm{e}_{\mathrm{aq}}{ }^{--}$generated with visible photons as a potentially very interesting alternative to gamma-ray ${ }^{45-47}$ or UVC-photon ${ }^{48,49}$ induced degradation methods for benzyltrialkylammonium compounds. Traditional monophotonic ionizations of inorganic anions with wavelengths around 250 $\mathrm{nm}^{29,50}$ would not be applicable to the conversion of both phenylcontaining substrates presented herein, because they are efficient light blockers below $300 \mathrm{~nm}$.

Compared to the only other system being able to produce $\mathrm{e}_{\mathrm{aq}}{ }^{\bullet-}$ with visible photons from a non-pulsed light source in homogeneous aqueous solution, ${ }^{13}$ our new $\mathrm{e}_{\mathrm{aq}}{ }^{\bullet-}$ source has despite operating through a different mechanism - both similar performance for applications and setup costs (with our setup being cheaper by about $50 \%$ ). Furthermore, both systems rely on a tailor-made metal complex catalyst. The more attractive reaction conditions of our system ( $\mathrm{pH}$ range from 7 to $10 \mathrm{vs}$. strongly alkaline solutions ${ }^{13}$ even able to attack glass), however, offer a decisive advantage. Under acidic conditions, the hydrated electrons would be quenched by protons, yielding less reactive hydrogen atoms.

Diode lasers currently have practically the same acquisition costs as comparable high-power LEDs suitable for immediate laboratory use (equipped with housing, cooling unit and power supply). Moreover, the usage of diode lasers operating in continuous wave (cw) mode is comparable to that of an LED, since $\mathrm{cw}$ lasers do not suffer from the health and safety hazards connected with pulsed lasers.

\section{CONCLUSIONS}

In summary, we have developed a new system for the catalytic generation of the superreductant $\mathrm{e}_{\mathrm{aq}}{ }^{\bullet-}$ under very attractive conditions and demonstrated its lab-scale application to challenging reductions of relevance for pharmaceutical research and for the degradation of environmentally problematic detergent components. Operating in pure water while only consuming blue photons from an inexpensive light source and an extremely cheap sacrificial donor, our novel $\mathrm{e}_{\mathrm{aq}}{ }^{\bullet-}$ source could further contribute to the ongoing rethinking of using green solvents such as water ${ }^{51,52}$. Given the current interest in two-photon phenomena, we anticipate that our first photoredox applications with a non-pulsed light source through the mechanism presented herein - the consecutive absorption of two photons with an excited state as intermediate - has important implications for future directions in harnessing light for challenging chemical reactions. Following the recent surge of interest in replacing precious one-photon catalysts, ${ }^{53-55}$ we think that our first example for the mechanism of Fig. 1b, which uses a precious Ir-based complex, could initiate the search for alternative (cheaper) photocatalysts with properties suitable for the consecutive two-photon absorption.

\section{ASSOCIATED CONTENT}

\section{Supporting Information}

The Supporting Information is available free of charge on the ACS Publications website at DOI: XXX.

General experimental details, additional results and control experiments, further laser flash photolysis data, and applicationrelated details (PDF).

\section{AUTHOR INFORMATION}

\section{Corresponding Authors}

christoph.kerzig@unibas.ch

oliver.wenger@unibas.ch

\section{Notes}

The authors declare no competing financial interests.

\section{ACKNOWLEDGMENT}

Financial support provided by the German National Academy of Sciences to CK (postdoctoral fellowship LPDS 2017-11) and by the Swiss NSF (grant number 200021_178760) to OSW is gratefully acknowledged.

\section{REFERENCES}

(1) Nguyen, J. D.; D’Amato, E. M.; Narayanam, J. M. R.; Stephenson, C. R. J. Engaging Unactivated Alkyl, Alkenyl and Aryl Iodides in VisibleLight-Mediated Free Radical Reactions. Nat. Chem. 2012, 4, 854-859.

(2) Ghosh, I.; Ghosh, T.; Bardagi, J. I.; König, B. Reduction of Aryl Halides by Consecutive Visible Light-Induced Electron Transfer Processes. Science 2014, 346, 725-728.

(3) Goez, M.; Kerzig, C.; Naumann, R. An “All-Green” Catalytic Cycle of Aqueous Photoionization. Angew. Chem. Int. Ed. 2014, 53, 9914-9916.

(4) Zeng, L.; Liu, T.; He, C.; Shi, D.; Zhang, F.; Duan, C. Organized Aggregation Makes Insoluble Perylene Diimide Efficient for the 
Reduction of Aryl Halides via Consecutive Visible Light-Induced Electron-Transfer Processes. J. Am. Chem. Soc. 2016, 138, 3958-3961.

(5) Ghosh, I.; König, B. Chromoselective Photocatalysis: Controlled Bond Activation through Light-Color Regulation of Redox Potentials. Angew. Chem. Int. Ed. 2016, 55, 7676-7679.

(6) Neumeier, M.; Sampedro, D.; Májek, M.; de la Peña O’Shea, V. A.; Jacobi von Wangelin, A.; Pérez-Ruiz, R. Dichromatic Photocatalytic Substitutions of Aryl Halides with a Small Organic Dye. Chem. Eur. J. 2018, 24, 105-108.

(7) Gong, H.-X.; Cao, Z.; Li, M.-H.; Liao, S.-H.; Lin, M.-J. Photoexcited Perylene Diimide Radical Anions for the Reduction of Aryl Halides: A Bay-Substituent Effect. Org. Chem. Front. 2018, 5, 22962302 .

(8) Meyer, A. U.; Slanina, T.; Heckel, A.; König, B. Lanthanide Ions Coupled with Photoinduced Electron Transfer Generate Strong Reduction Potentials from Visible Light. Chem. Eur. J. 2017, 23, 7900-7904.

(9) Haimerl, J.; Ghosh, I.; König, B.; Vogelsang, J.; Lupton, J. M. Single-Molecule Photoredox Catalysis. Chem. Sci. 2019, DOI: 10.1039/C8SC03860K.

(10) Naumann, R.; Kerzig, C.; Goez, M. Laboratory-Scale Photoredox Catalysis Using Hydrated Electrons Sustainably Generated with a Single Green Laser. Chem. Sci. 2017, 8, 7510-7520.

(11) Naumann, R.; Lehmann, F.; Goez, M. Generating Hydrated Electrons for Chemical Syntheses by Using a Green Light-Emitting Diode (LED). Angew. Chem. Int. Ed. 2018, 57, 1078-1081.

(12) Naumann, R.; Lehmann, F.; Goez, M. Micellized Tris(bipyridine)ruthenium Catalysts Affording Preparative Amounts of Hydrated Electrons with a Green Light-Emitting Diode. Chem. Eur. J. 2018, 24, 13259-13269.

(13) Naumann, R.; Goez, M. First Micelle-Free Photoredox Catalytic Access to Hydrated Electrons for Syntheses and Remediations with a Visible LED or Even Sunlight. Chem. Eur. J. 2018, 24, 17557-17567.

(14) Häring, M.; Pérez-Ruiz, R.; Jacobi von Wangelin, A.; Díaz, D. D. Intragel Photoreduction of Aryl Halides by Green-to-Blue Upconversion under Aerobic Conditions. Chem. Commun. 2015, 51, 16848-16851.

(15) Aguirre-Soto, A.; Kaastrup, K.; Kim, S.; Ugo-Beke, K.; Sikes, H. D. Excitation of Metastable Intermediates in Organic Photoredox Catalysis: Z-Scheme Approach Decreases Catalyst Inactivation. ACS Catal. 2018, 8, 6394-6400.

(16) López-Calixto, C. G.; Liras, M.; de la Peña O’Shea, V. A.; PérezRuiz, R. Synchronized Biphotonic Process Triggering C-C Coupling Catalytic Reactions. Appl. Catal. B 2018, 237, 18-23.

(17) Slanina, T.; Oberschmid, T. Rhodamine 6G Radical: A Spectro (Fluoro) Electrochemical and Transient Spectroscopic Study. ChemCatChem 2018, 10, 4182-4190.

(18) Marchini, M.; Gualandi, A.; Mengozzi, L.; Franchi, P.; Lucarini, M.; Cozzi, P. G.; Balzani, V.; Ceroni, P. Mechanistic Insights into TwoPhoton-Driven Photocatalysis in Organic Synthesis. Phys. Chem. Chem. Phys. 2018, 20, 8071-8076.

(19) Kerzig, C.; Wenger, O. S. Sensitized Triplet-Triplet Annihilation Upconversion in Water and Its Application to Photochemical Transformations. Chem. Sci. 2018, 9, 6670-6678.

(20) Kobayashi, Y.; Mutoh, K.; Abe, J. Stepwise Two-Photon Absorption Processes Utilizing Photochromic Reactions. J. Photochem. Photobiol. C 2018, 34, 2-28.

(21) Seegerer, A.; Nitschke, P.; Gschwind, R. M. Combined In Situ Illumination-NMR-UV/Vis Spectroscopy: A New Mechanistic Tool in Photochemistry. Angew. Chem. Int. Ed. 2018, 57, 7493-7497.

(22) Christensen, J. A.; Phelan, B. T.; Chaudhuri, S.; Acharya, A.; Batista, V. S.; Wasielewski, M. R. Phenothiazine Radical Cation Excited States as Super-Oxidants for Energy-Demanding Reactions. J. Am. Chem. Soc. 2018, 140, 5290-5299.

(23) Fujitsuka, M.; Majima, T. Reaction Dynamics of Excited Radical Ions Revealed by Femtosecond Laser Flash Photolysis. J. Photochem. Photobiol. C 2018, 35, 25-37.

(24) Hu, A.; Chen, Y.; Guo, J.-J.; Yu, N.; An, Q.; Zuo, Z. CeriumCatalyzed Formal Cycloaddition of Cycloalkanols with Alkenes through Dual Photoexcitation. J. Am. Chem. Soc. 2018, 140, 13580-13585.

(25) Rauch, M. P.; Knowles, R. R. Applications and Prospects for Triplet-Triplet Annihilation Photon Upconversion. Chimia 2018, 72, 501507.

(26) Buxton, G. V.; Greenstock, C. L.; Helman, W. P.; Ross, A. B. Critical Review of Rate Constants for Reactions of Hydrated Electrons, Hydrogen Atoms and Hydroxyl Radicals in Aqueous Solution. J. Phys. Chem. Ref. Data 1988, 17, 513-886.
(27) Kohlmann, T.; Naumann, R.; Kerzig, C.; Goez, M. 3Aminoperylene and Ascorbate in Aqueous SDS, One Green Laser Flash ... and Action! Sustainably Detoxifying a Recalcitrant Chloro-Organic. Photochem. Photobiol. Sci. 2017, 16, 1613-1622.

(28) Kerzig, C.; Goez, M. Combining Energy and Electron Transfer in a Supramolecular Environment for the "Green" Generation and Utilization of Hydrated Electrons through Photoredox Catalysis. Chem. Sci. 2016, 7, 3862-3868

(29) Li, X.; Ma, J.; Liu, G.; Fang, J.; Yue, S.; Guan, Y.; Chen, L.; Liu, X. Efficient Reductive Dechlorination of Monochloroacetic Acid by Sulfite/UV Process. Environ. Sci. Technol. 2012, 46, 7342-7349.

(30) Zhu, D.; Zhang, L.; Ruther, R. E.; Hamers, R. J. Photo-Illuminated Diamond as a Solid-State Source of Solvated Electrons in Water for Nitrogen Reduction. Nat. Mater. 2013, 12, 836-841.

(31) Zhang, L.; Zhu, D.; Nathanson, G. M.; Hamers, R. J. Selective Photoelectrochemical Reduction of Aqueous $\mathrm{CO}_{2}$ to $\mathrm{CO}$ by Solvated Electrons. Angew. Chem. Int. Ed. 2014, 53, 9746-9750.

(32) Guo, X.; Okamoto, Y.; Schreier, M. R.; Ward, T. R.; Wenger, O. S. Enantioselective Synthesis of Amines by Combining Photoredox and Enzymatic Catalysis in a Cyclic Reaction Network. Chem. Sci. 2018, 9, 5052-5056.

(33) Flamigni, L.; Barbieri, A.; Sabatini, C.; Ventura, B.; Barigelletti, F. Photochemistry and Photophysics of Coordination Compounds: Iridium. Top. Curr. Chem. 2007, 281, 143-203.

(34) Campagna, S.; Puntoriero, F.; Nastasi, F.; Bergamini, G.; Balzani, V. Photochemistry and Photophysics of Coordination Compounds: Ruthenium. Top. Curr. Chem. 2007, 280, 117-214.

(35) Müller, P.; Brettel, K. $\left[\mathrm{Ru}(\mathrm{bpy})_{3}\right]^{2+}$ as a Reference in Transient Absorption Spectroscopy: Differential Absorption Coefficients for Formation of the Long-Lived ${ }^{3}$ MLCT Excited State. Photochem. Photobiol. Sci. 2012, 11, 632-636.

(36) Tarnovsky, A. N.; Gawelda, W.; Johnson, M.; Bressler, C.; Chergui, M. Photexcitation of Aqueous Ruthenium(II)-tris-(2,2‘ bipyridine) with High-Intensity Femtosecond Laser Pulses. J. Phys. Chem. $B$ 2006, 110, 26497-26505.

(37) Tran, T.-T.; Ha-Thi, M.-H.; Pino, T.; Quaranta, A.; Lefumeux, C.; Leibl, W.; Aukauloo, A. Snapshots of Light Induced Accumulation of Two Charges on Methylviologen Using a Sequential Nanosecond PumpPump Photoexcitation. J. Phys. Chem. Lett. 2018, 9, 1086-1091.

(38) Redmond, R. W.; Scaiano, J. C.; Johnston, L. J. Photochemistry of Diphenylketyl Radicals in Polar Solvents. J. Am. Chem. Soc. 1990, 112, 398-402.

(39) Jaroschik, F. Picking One out of Three: Selective Single C-F Activation in Trifluoromethyl Groups. Chem. Eur. J. 2018, 24, 1457214582.

(40) Chen, K.; Berg, N.; Gschwind, R.; König, B. Selective Single $\mathrm{C}\left(\mathrm{Sp}^{3}\right)-\mathrm{F}$ Bond Cleavage in Trifluoromethylarenes: Merging VisibleLight Catalysis with Lewis Acid Activation. J. Am. Chem. Soc. 2017, 139, $18444-18447$.

(41) Ma, J.; Yi, W.; Lu, G.; Cai, C. Transition-Metal-Free C-H Oxidative Activation: Persulfate-Promoted Selective Benzylic Mono- and Difluorination. Org. Biomol. Chem. 2015, 13, 2890-2894.

(42) van der Born, D.; Sewing, C.; Herscheid, J. K. D. M.; Windhorst, A. D.; Orru, R. V. A.; Vugts, D. J. A Universal Procedure for the $\left[{ }^{18} \mathrm{~F}\right]$ Trifluoromethylation of Aryl Iodides and Aryl Boronic Acids with Highly Improved Specific Activity. Angew. Chem. Int. Ed. 2014, 53, 11046-11050.

(43) Anbar, M.; Hart, E. J. The Reactivity of Aromatic Compounds toward Hydrated Electrons. J. Am. Chem. Soc. 1964, 86, 5633-5637.

(44) Loh, Y. Y.; Nagao, K.; Hoover, A. J.; Hesk, D.; Rivera, N. R.; Colletti, S. L.; Davies, I. W.; MacMillan, D. W. C. Photoredox-Catalyzed Deuteration and Tritiation of Pharmaceutical Compounds. Science 2017, $358,1182-1187$.

(45) Tezel, U.; Pavlostathis, S. G. Quaternary Ammonium Disinfectants: Microbial Adaptation, Degradation and Ecology. Curr. Opin.

Biotechnol. 2015, 33, 296-304.

(46) Bobrowski, K. Pulse Radiolysis of Aqueous Solutions of Benzyltrialkylammonium Cations. Reactions with the Primary Transients from Water Radiolysis. J. Phys. Chem. 1981, 85, 382-388.

(47) Xu, Z.; Zhang, X.; Huang, N.; Hu, H. Oxidation of Benzalkonium Chloride by Gamma Irradiation: Kinetics and Decrease in Toxicity. J. Radioanal. Nucl. Chem. 2017, 312, 631-637.

(48) Huang, N.; Wang, T.; Wang, W.-L.; Wu, Q.-Y.; Li, A.; Hu, H.-Y. $\mathrm{UV} / \mathrm{Ch}$ lorine as an Advanced Oxidation Process for the Degradation of 
Benzalkonium Chloride: Synergistic Effect, Transformation Products and Toxicity Evaluation. Water Res. 2017, 114, 246-253.

(49) Lee, M.-Y.; Wang, W.-L.; Wu, Q.-Y.; Huang, N.; Xu, Z.-B.; Hu, H.-Y. Degradation of Dodecyl Dimethyl Benzyl Ammonium Chloride (DDBAC) as a Non-Oxidizing Biocide in Reverse Osmosis System Using UV/Persulfate: Kinetics, Degradation Pathways, and Toxicity Evaluation. Chem. Eng. J. 2018, 352, 283-292.

(50) Gu, Y.; Dong, W.; Luo, C.; Liu, T. Efficient Reductive Decomposition of Perfluorooctanesulfonate in a High Photon Flux UV/Sulfite System. Environ. Sci. Technol. 2016, 50, 10554-10561.

(51) Yu, H.; Ru, S.; Dai, G.; Zhai, Y.; Lin, H.; Han, S.; Wei, Y. An Efficient Iron(III)-Catalyzed Aerobic Oxidation of Aldehydes in Water for the Green Preparation of Carboxylic Acids. Angew. Chem. Int. Ed. 2017, $56,3867-3871$
(52) Lippincott, D. J.; Linstadt, R. T. H.; Maser, M. R.; Gallou, F.; Lipshutz, B. H. Synthesis of Functionalized 1,3-Butadienes via PdCatalyzed Cross-Couplings of Substituted Allenic Esters in Water at Room Temperature. Org. Lett. 2018, 20, 4719-4722.

(53) Wenger, O. S. Photoactive Complexes with Earth-Abundant Metals. J. Am. Chem. Soc. 2018, $140,13522-13533$.

(54) Du, Y.; Pearson, R. M.; Lim, C.-H.; Sartor, S. M.; Ryan, M. D.; Yang, H.; Damrauer, N. H.; Miyake, G. M. Strongly Reducing, VisibleLight Organic Photoredox Catalysts as Sustainable Alternatives to Precious Metals. Chem. Eur. J. 2017, 23, 10962-10968.

(55) Qiao, Y.; Schelter, E. J. Lanthanide Photocatalysis. Acc. Chem. Res. 2018, 51, 2926-2936. 


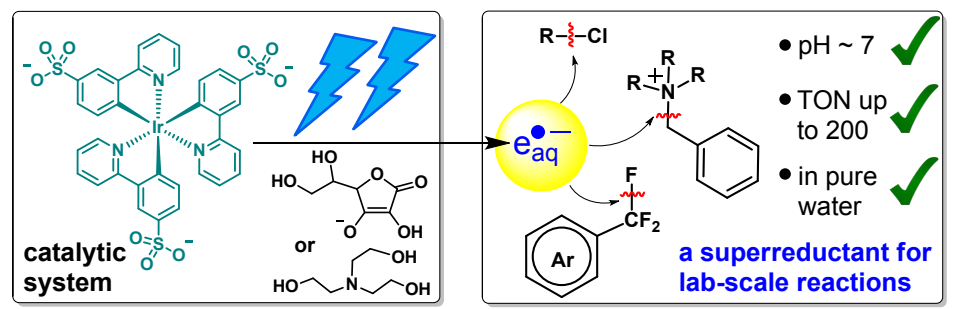

10

11

12

13

14

15

16

17

18

19

20

21

22

23 